\title{
Prostatic relaxation induced by loperamide is mediated through activation of opioid $\mu-2$ receptors in vitro
}

\author{
CHIH-CHENG LU ${ }^{1}$, HSIEN-HUI CHUNG ${ }^{2}$ and JUEI-TANG CHENG ${ }^{2,3}$ \\ ${ }^{1}$ Department of Surgery, Chi-Mei Medical Center, Liou-Ying; \\ ${ }^{2}$ Institute of Basic Medical Sciences, College of Medicine, National Cheng Kung University; \\ ${ }^{3}$ Department of Medical Research, Chi-Mei Medical Center, Yong Kang, Tainan, Taiwan, R.O.C.
}

Received October 12, 2010; Accepted December 6, 2010

DOI: $10.3892 /$ etm.2011.201

\begin{abstract}
The merit of opioid $\mu$-receptor activation in the improvement of benign prostatic hyperplasia $(\mathrm{BPH})$ remains obscure. In the present study, we used loperamide to identify the subtype of opioid $\mu$-receptors involved in prostatic relaxation and investigate the possible mechanism of this relaxation. Prostate strips were isolated from 12-week-old male Wistar rats for identification of isometric tension. The prostate strips were precontracted with either $1 \mu \mathrm{mol} / 1$ phenylephrine or $50 \mathrm{mmol} / 1$ $\mathrm{KCl}$. The decrease in muscle tone (relaxation) was then characterized after cumulative administration of loperamide $(0.1$ to $10 \mu \mathrm{mol} / \mathrm{l}$ ) into the organ bath for the concentration-dependent study. Pretreatment with specific blockers or antagonists was carried out to compare the changes in loperamide-induced relaxation. Loperamide produced a marked relaxation in the isolated prostates precontracted with phenylephrine or $\mathrm{KCl}$ in a dose-dependent manner. This relaxation was abolished by cyprodime, a selective opioid $\mu$-receptor antagonist, but was not modified by naloxonazine at a dose sufficient to block the opioid $\mu-1$ receptors. Treatment with an agonist for opioid $\mu-1$ receptors also failed to modify the muscle tone. Moreover, the relaxation by loperamide was attenuated by glibenclamide at a dose sufficient to block ATP-sensitive $\mathrm{K}^{+}$channels. In addition, this action of loperamide was abolished by protein kinase A (PKA) inhibitor and enhanced by the inhibitor of phosphodiesterase for cyclic AMP (cAMP). Our results suggest that loperamide induces prostatic relaxation through activation of opioid $\mu$-2 receptors via the cAMP-PKA pathway to open ATP-sensitive $\mathrm{K}^{+}$channels.
\end{abstract}

Correspondence to: Professor Juei-Tang Cheng, Department of Medical Research, Chi-Mei Medical Center, Yong Kang, Tainan, Taiwan, R.O.C.

E-mail:m980103@mail.chimei.org.tw

Key words: ATP-sensitive $\mathrm{K}^{+}$channels, isometric tension, loperamide, $\mu$-opioid receptors, rat prostate

\section{Introduction}

Benign prostatic hyperplasia (BPH) occurs frequently in older men and is associated with lower urinary tract symptoms causing obstruction of the proximal urethra and urinary flow disturbances (1). In clinics, medical treatments for BPH include widely used $\alpha-1$ antagonists and 5- $\alpha$-reductase inhibitors. However, the side effects, such as postural hypotension, erectile dysfunction and ejaculatory difficulty, disturb the quality of life of these patients $(2,3)$. Therefore, development of a more effective therapy for the treatment of $\mathrm{BPH}$ is urgent and necessary.

Loperamide is widely used in the clinic for a variety of diarrheal syndromes, including acute and nonspecific (infectious) diarrhea (4,5). Recently, we identified opioid $\mu$-receptor expression in rat prostates, and prostatic relaxation was induced by the activation of opioid $\mu$-receptors using loperamide (6). Loperamide was introduced as a peripheral agonist of opioid $\mu$-receptors with poor ability to penetrate the bloodbrain barrier $(7,8)$. Some analgesic agents have also revealed relaxant effects in smooth muscle $(9,10)$. (+)-Tramadol was found to activate peripheral opioid $\mu$-receptors to exhibit a concentration-dependent relaxation of aorta (11). Basically, the opioid $\mu$-receptors have been divided into 3 subtypes, including $\mu-1, \mu-2$ and $\mu-3$ opioid receptors (12). However, activation of opioid $\mu-1$ receptors was reported to be link mainly with the PLC-PKC pathway (13). Since PLC-PKC signals increase intracellular calcium to induce vasoconstriction or bladder contraction $(14,15)$, prostatic relaxation ia not considered to be induced by the activation of opioid $\mu-1$ receptors.

ATP-sensitive $\mathrm{K}^{+}\left(\mathrm{K}_{\mathrm{ATP}}\right)$ channels have been found to be involved in the relaxation of urethral smooth muscle (16). Actually, the opening of the $\mathrm{K}_{\text {ATP }}$ channel is introduced to lower intracellular $\mathrm{Ca}^{+}$concentrations $(17,18)$. Moreover, impairment of the $\mathrm{K}_{\text {ATP }}$ channel appears to be associated with the dysfunction of the lower urinary tract (19). However, the role of the $\mathrm{K}_{\mathrm{ATP}}$ channel in prostatic relaxation remains obscure.

In an attempt to clarify the subtype of opioid $\mu$-receptor involved in the regulation of prostatic tone, we used loperamide as an agonist in order to induce relaxation in isolated prostates. Specific blockers or antagonists were then applied to investigate the possible mechanism(s) of loperamide. 


\section{Materials and methods}

Experimental animals. We obtained 12-week-old male Wistar rats from the Animal Center of National Cheng Kung University Medical College. Rats were maintained in a temperature-controlled room $\left(25 \pm 1^{\circ} \mathrm{C}\right)$ under a $12 \mathrm{~h}$ lightdark cycle (lights on at 06:00). All rats were given water and fed standard chow (Purina Mills, LLC, St. Louis, MO, USA) ad libitum. All animal-handling procedures were performed according to the Guide for the Care and Use of Laboratory Animals of the National Institutes of Health, as well as the Guidelines of the Animal Welfare Act.

Preparation of isolated prostate strips. In all prostatic experiments, the isolated prostates from Wistar rats were used. Each rat was sacrificed by decapitation under anesthesia with pentobarbital $(50 \mathrm{mg} / \mathrm{kg})$. Following our previous study, the prostate strips were rapidly removed and placed in oxygenated Krebs' buffer $\left(95 \% \mathrm{O}_{2}, 5 \% \mathrm{CO}_{2}\right)$. After the prostate strips were carefully freed from fat and connective tissue, the strips were then mounted in organ baths filled with $10 \mathrm{ml}$ of oxygenated Krebs' buffer $\left(95 \% \mathrm{O}_{2}, 5 \% \mathrm{CO}_{2}\right.$ ) at $37^{\circ} \mathrm{C}$ containing (in mmol/l) $\mathrm{NaCl}$ 135; $\mathrm{KCl} 5 ; \mathrm{CaCl}_{2} 2.5 ; \mathrm{MgSO}_{4} 1.3 ; \mathrm{KH}_{2} \mathrm{PO}_{4} 1.2 ; \mathrm{NaHCO}_{3} 20$; and D-glucose 10 (pH 7.4).

Each preparation was connected to strain gauges (FT03; Grass Instrument, Quincy, MA, USA). Isometric tension was recorded using Chart software (MLS023, Powerlab; ADInstruments, Bella Vista, NSW, Australia). Strips were mounted and allowed to stabilize for $2 \mathrm{~h}$. Each preparation was then gradually stretched to achieve an optimal resting tension of $0.5 \mathrm{~g}$.

Prostatic relaxation caused by loperamide. After the resting tension had stabilized, a solution of phenylephrine (Sigma-Aldrich, St. Louis, MO, USA) or $\mathrm{KCl}$ prepared in distilled water was added into bathing buffer to induce a rapid increase in prostatic tone followed by stable constriction (tonic contraction). The final concentration in the organ bath for phenylephrine was $1 \mu \mathrm{mol} / 1$ and for $\mathrm{KCl}, 50 \mathrm{mmol} / \mathrm{l}$, respectively. Prostate strips in the treatment group were exposed to loperamide $(0.1-10 \mu \mathrm{mol} / \mathrm{l})$ to observe the decrease in tonic contraction (vasodilatation). Relaxation was expressed as the percent decrease in maximal tonic contraction. Concentration-relaxation curves were generated in cumulative fashion.

Effects of blockers on loperamide-induced prostatic relaxation. Prostate strips were exposed to glibenclamide (Research Biochemical, Wayland, MA, USA) or opioid $\mu$-receptor antagonist, cyprodime or naloxonazine (Tocris Cookson, Bristol, UK), for $15 \mathrm{~min}$ before the addition of loperamide into the organ bath. In addition, the inhibitor of cyclic AMP phosphodiesterase (IBMX) or protein kinase A (H-89) was administered in the same manner. Changes in relaxation caused by loperamide were compared with that in the vehicle (distilled water)-treated controls.

Statistical analysis. All values are presented as the mean \pm SEM for a given number of animals or samples. Analysis of variance and Dunnett's post hoc test were used to evaluate the

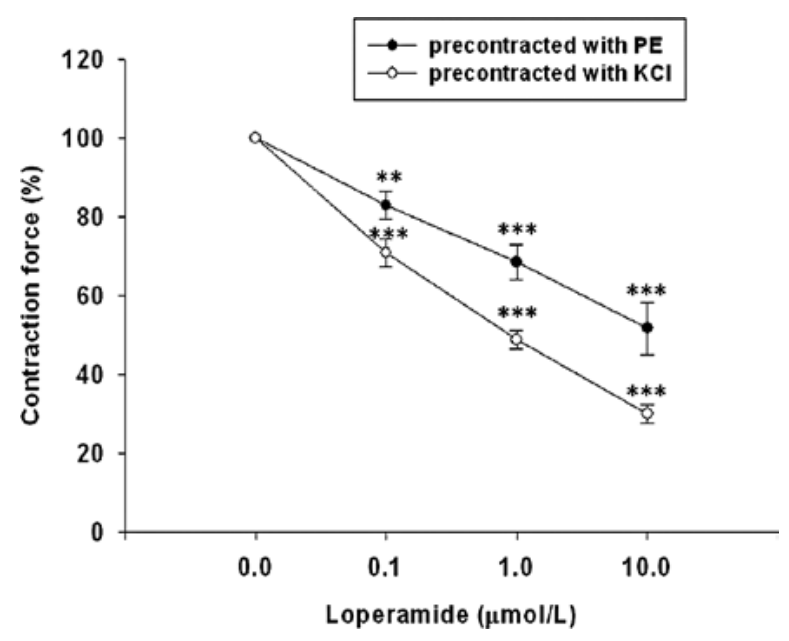

Figure 1. Concentration-dependent relaxation induced by loperamide in isolated prostate strips precontracted with $1 \mu \mathrm{mol} / 1$ phenylephrine or $50 \mathrm{mmol} / 1$ $\mathrm{KCl}$. Data represent the mean \pm SEM of eight animals. ${ }^{* * *} \mathrm{P}<0.001$ compared with the vehicle (distilled water)-treated control.

significance between groups. $\mathrm{P}<0.05$ was considered to be a significant difference.

\section{Results}

Effect of opioid receptor blockade on loperamide-induced prostatic relaxation. Prostate strips were strongly contracted by the application of phenylephrine $(1 \mu \mathrm{mol} / \mathrm{l})$ or $\mathrm{KCl}$ (50 mmol/l). As shown in Fig. 1, loperamide dilated both phenylephrine- and $\mathrm{KCl}$-contracted prostate strips in a concentration-dependent manner. At the maximal concentration tested $(10 \mu \mathrm{mol} / \mathrm{l})$, loperamide significantly attenuated the tonic contraction of prostate strips induced by phenylephrine to $52.79 \pm 6.10 \%$ of the maximal contraction. Similarly, $10 \mu \mathrm{mol} / 1$ loperamide also lowered $\mathrm{KCl}$-induced tonic constriction to $30.06 \pm 2.19 \%$ of the maximal contraction. Cyprodime (0.01-0.1 $\mu \mathrm{mol} / \mathrm{l})$ produced a significant and concentrationdependent attenuation of the relaxant effect of loperamide on the tonic contraction of phenylephrine-precontracted prostate strips. The prostatic relaxation due to loperamide in $\mathrm{KCl}$-pretreated prostate strips was also abolished in a similar manner in the presence of cyprodime (Table I). In addition, naloxonazine failed to abolish the relaxant effect of loperamide on tonic contraction in phenylephrine $(1 \mu \mathrm{mol} / \mathrm{l})$ precontracted prostate strips at a higher concentration $(0.1 \mu \mathrm{mol} / \mathrm{l})$. As shown in Table I, the prostatic relaxation by loperamide in $\mathrm{KCl}(50 \mathrm{mmol} / \mathrm{l})$-precontracted prostate strips was also not reversed by naloxonazine even at a higher concentration. Also, treatment with stevioside at a dose sufficient to activate the opioid $\mu-1$ receptor as described previously (20) failed to modify muscle tone in either the phenylephrine- or $\mathrm{KCl}$-contracted prostate strips (Fig. 2).

Role of ATP-sensitive $K^{+}\left(K_{A T P}\right)$ channels in loperamideinduced prostatic relaxation. Glibenclamide produced a concentration-dependent $(0.01-1 \quad \mu \mathrm{mol} / \mathrm{l})$ attenuation of the relaxant effect of loperamide on tonic contraction of phenylephrine $(1 \mu \mathrm{mol} / \mathrm{l})$-precontracted prostate strips. The 
Table I. Inhibitory effect of cyprodime or naloxonazine on the relaxation of loperamide $(10 \mu \mathrm{mol} / \mathrm{l})$ in isolated prostates precontracted with $1 \mu \mathrm{mol} / 1$ phenylephrine (PE) or $50 \mathrm{mmol} / \mathrm{K} \mathrm{KCl}$.

\begin{tabular}{lcc}
\hline & $\mathrm{PE}(\%)$ & $\mathrm{KCl}(\%)$ \\
\hline $\begin{array}{l}\text { Loperamide }(10 \mu \mathrm{mol} / \mathrm{l}) \\
\text { + Vehicle }\end{array}$ & $55.49 \pm 6.16$ & $35.18 \pm 3.30$ \\
+ Cyprodime & & \\
$0.01 \mu \mathrm{mol} / 1$ & $76.48 \pm 1.75^{\mathrm{b}}$ & $72.58 \pm 1.47^{\mathrm{c}}$ \\
$0.10 \mu \mathrm{mol} / 1$ & $90.69 \pm 0.80^{\mathrm{c}}$ & $87.59 \pm 0.47^{\mathrm{c}}$ \\
+ Naloxonazine & & \\
$0.01 \mu \mathrm{mol} / 1$ & $57.90 \pm 2.73$ & $38.58 \pm 3.38$ \\
$0.10 \mu \mathrm{mol} / 1$ & $66.97 \pm 1.31$ & $41.17 \pm 3.93$ \\
\hline
\end{tabular}

Data represent the mean \pm SEM of eight animals. ${ }^{\mathrm{a}} \mathrm{P}<0.05,{ }^{\mathrm{b}} \mathrm{P}<0.01$ and ${ }^{\mathrm{C}} \mathrm{P}<0.001$ compared with the vehicle-treated control.

Table II. Effects of the inhibitors for cAMP phosphodiesterase or protein kinase A (PKA) on relaxation induced by loperamide $(10 \mu \mathrm{mol} / \mathrm{l})$ or forskolin $(10 \mu \mathrm{mol} / \mathrm{l})$ in isolated prostates precontracted with $1 \mu \mathrm{mol} / 1$ phenylephrine (PE) or $50 \mathrm{mmol} / \mathrm{K} \mathrm{KCl}$.

$$
\mathrm{PE}(\%) \quad \mathrm{KCl}(\%)
$$

\begin{tabular}{lll}
$\begin{array}{l}\text { Loperamide }(10 \mu \mathrm{mol} / \mathrm{l}) \\
\text { + Vehicle }\end{array}$ & $59.69 \pm 3.54$ & $33.08 \pm 1.89$ \\
+ IBMX $(10 \mu \mathrm{mol} / \mathrm{l})$ & $46.58 \pm 1.87^{\mathrm{b}}$ & $25.12 \pm 0.86^{\mathrm{b}}$ \\
+ H-89 $(1 \mu \mathrm{mol} / \mathrm{l})$ & $86.22 \pm 2.10^{\mathrm{c}}$ & $85.00 \pm 0.58^{\mathrm{c}}$ \\
Forskolin $(10 \mu \mathrm{mol} / \mathrm{l})$ & & \\
+ Vehicle & $28.47 \pm 1.83$ & $24.48 \pm 1.92$ \\
+ Glibenclamide $(1 \mu \mathrm{mol} / \mathrm{l})$ & $83.17 \pm 2.17^{\mathrm{c}}$ & $80.21 \pm 1.77^{\mathrm{c}}$ \\
+ IBMX $(10 \mu \mathrm{mol} / 1)$ & $11.69 \pm 1.29^{\mathrm{c}}$ & $10.47 \pm 0.28^{\mathrm{c}}$ \\
+ H-89 $(1 \mu \mathrm{mol} / \mathrm{l})$ & $86.08 \pm 1.69^{\mathrm{c}}$ & $83.03 \pm 1.17^{\mathrm{c}}$ \\
IBMX $(10 \mu \mathrm{mol} / \mathrm{l})$ & $94.64 \pm 0.88^{\mathrm{c}}$ & $90.26 \pm 1.01^{\mathrm{c}}$ \\
H-89 $(1 \mu \mathrm{mol} / \mathrm{l})$ & $95.78 \pm 1.07^{\mathrm{c}}$ & $91.25 \pm 1.18^{\mathrm{c}}$ \\
Glibenclamide $(1 \mu \mathrm{mol} / \mathrm{l})$ & $95.79 \pm 1.16^{\mathrm{c}}$ & $90.32 \pm 0.69^{\mathrm{c}}$ \\
\hline
\end{tabular}

Data represent the mean \pm SEM of eight animals. ${ }^{\mathrm{P} P}<0.05,{ }^{\mathrm{b}} \mathrm{P}<0.01$ and ${ }^{\mathrm{c}} \mathrm{P}<0.001$ compared with the vehicle-treated control, respectively.

prostatic relaxation by loperamide in $\mathrm{KCl}(50 \mathrm{mmol} / \mathrm{l})$-pretreated prostate strips was also abolished in a similar manner by the treatment of glibenclamide (Fig. 3).

Role of cAMP and PKA in loperamide-induced prostatic relaxation. In the present study, forskolin $(10 \mu \mathrm{mol} / 1)$, a direct activator of adenylate cyclase, was used as a positive control to increase cyclic AMP (cAMP) as described previously (21). In prostate strips precontracted with phenylephrine $(1 \mu \mathrm{mol} / \mathrm{l})$ or $\mathrm{KCl}(50 \mathrm{mmol} / \mathrm{l})$, forskolin-induced relaxation was also abolished by pretreatment with glibenclamide $(1 \mu \mathrm{mol} / \mathrm{l})$.
$\mathbf{A}$
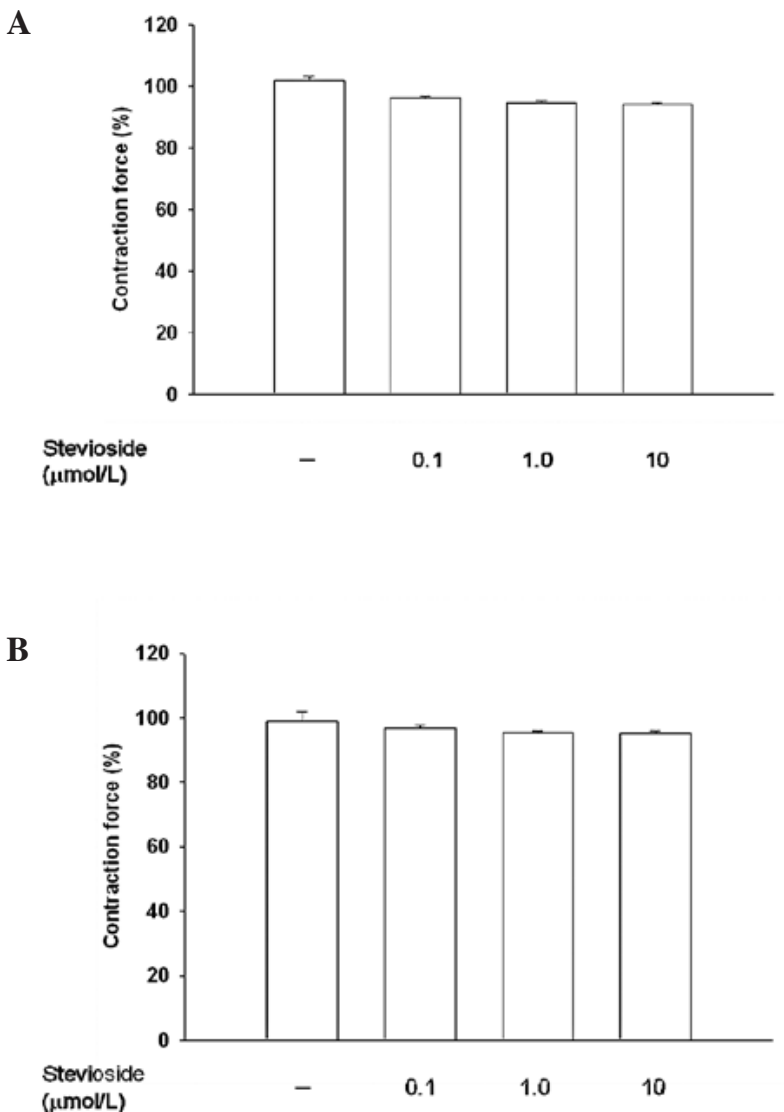

Figure 2. Effect of stevioside on the muscle tone in isolated prostate strips precontracted with $1 \mu \mathrm{mol} / 1$ phenylephrine (A) or $50 \mathrm{mmol} / 1 \mathrm{KCl}$ (B). Data represent the mean \pm SEM of eight animals. No difference was observed as compared with the vehicle (distilled water)-treated control.

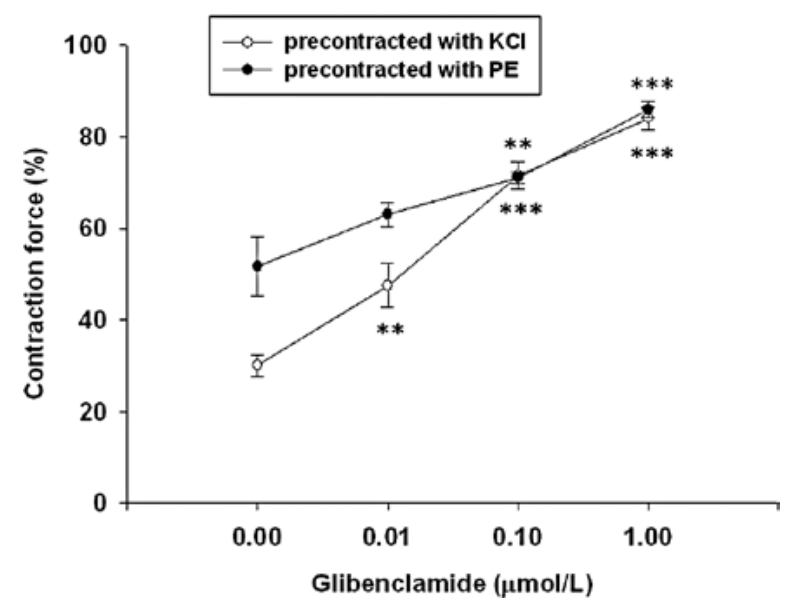

Figure 3. Concentration-dependent inhibitory effect of glibenclamide on the relaxation induced by loperamide $(10 \mu \mathrm{mol} / \mathrm{l})$ in isolated prostates precontracted with $1 \mu \mathrm{mol} / 1$ phenylephrine or $50 \mathrm{mmol} / \mathrm{l} \mathrm{KCl}$. Data represent the mean \pm SEM of eight animals. ${ }^{*} \mathrm{P}<0.05,{ }^{* *} \mathrm{P}<0.01$ and ${ }^{* * *} \mathrm{P}<0.001$ compared with the vehicle-treated control.

Moreover, prostatic relaxation by forskolin was increased by 3-isobutyl-1-methylxanthine (IBMX) at a concentration $(10 \mu \mathrm{mol} / \mathrm{l})$ sufficient to inhibit cAMP-phosphodiesterase (22), and was decreased by H-89 at a concentration $(1 \mu \mathrm{mol} / \mathrm{l})$ enough to abolish the protein kinase A (PKA) (23). The 
loperamide-induced prostatic relaxation was also modified by these agents in a similar manner. Results showed that prostatic relaxation induced by loperamide was increased by IBMX and attenuated by H-89 (Table II).

\section{Discussion}

In the present study, we found that loperamide caused a dose-dependent relaxation in prostate strips of rats precontracted with phenylephrine or $\mathrm{KCl}$. The action of loperamide appears to be related to the activation of opioid receptors in peripheral tissue as loperamide does not cross the central nervous system (8). Moreover, loperamide-induced action is effectively abolished by cyprodime, suggesting an activation of opioid $\mu$-receptors by loperamide in prostatic relaxation. However, the action of loperamide was not reversed by naloxonazine even at the dose sufficient to block opioid $\mu-1$ receptors. In addition, relaxation was not induced by agonist specific for opioid $\mu-1$ receptors (Fig. 2). Thus, mediation of opioid $\mu$-1 receptors was unlikely involved in the prostatic relaxation of loperamide.

Thus, another opioid $\mu$-receptor involved in this action of loperamide was considered. There is no doubt that loperamide is an agonist of peripheral opioid $\mu$-receptors $(8,24)$. Recently, the opioid $\mu$-receptors have been divided into 3 subtypes, including $\mu-1, \mu-2$ and $\mu-3$ (25-27). Analgesic action through the activation of opioid $\mu-1$ receptors has been reported to exert spinal antinociception $(28,29)$. In addition, activation of the opioid $\mu$-1 receptors seems to be related to smooth muscle contraction via the PLC-PKC pathway $(14,15)$. Activation of the opioid $\mu-2$ receptors was found to participate in the relaxation of guinea pig ileum and inhibition of gastrointestinal transit $(30,31)$. Moreover, opioid $\mu-3$ receptors are mostly present in endothelial cells associated with the production of nitric oxide to induce vasodilatation (32). Therefore, mediation of opioid $\mu-1$ or $\mu-3$ receptors in prostatic relaxation seems unlikely. Taken together, an activation of opioid $\mu-2$ receptors is more likely to participate in the action of loperamide in the relaxation of isolated prostate strips. Since there is no suitable tool or agent which can aid us in identifying this receptor, we focused on the subcellular signals of this receptor as an alternative method.

Potassium channels play an important role in the regulation of prostatic contractility in guinea-pig prostate smooth muscle cells (33). In a previous study, potassium channel expression was reduced in human $\mathrm{BPH}$ and prostate cancer (34). Moreover, the ATP-sensitive $\mathrm{K}^{+}\left(\mathrm{K}_{\mathrm{ATP}}\right)$ channels are composed of four inwardly rectifying $\mathrm{K}^{+}$channel subunits and four regulatory sulphonylurea receptors (35). The activation of $\mathrm{K}_{\mathrm{ATP}}$ channels causes hyperpolarization of the cell membrane and consequently relaxes smooth muscle. In our previous study $(36,37)$, the relaxation of loperamide in rat prostate strips was abolished by the pretreatment with glibenclamide at a concentration sufficient to block $\mathrm{K}_{\mathrm{ATP}}$ channels. Thus, we focused on the involvement of $\mathrm{K}_{\mathrm{ATP}}$ channels in the prostatic relaxation induced by loperamide. We then applied forskolin as a positive reference since forskolin was introduced as a direct activator of adenylate cyclase which can increase the intracellular cyclic AMP (cAMP) to activate cAMP-dependent protein kinase (PKA) for opening $\mathrm{K}_{\mathrm{ATP}}$ channels (23).
As shown in Table II, we determined that forskolin-induced prostatic relaxation was also blocked by glibenclamide. The prostatic relaxation of forskolin was abolished by $\mathrm{H}-89$ at a concentration sufficient to block PKA (23) and was enhanced by IBMX at a concentration sufficient to inhibit cAMPphosphodiesterase (22). Similar results were also observed in prostate strips relaxed by loperamide (Table II). These data suggest that the possible mechanism for loperamide-induced prostatic relaxation is mediated through the cAMP-PKA pathway to open $\mathrm{K}_{\mathrm{ATP}}$ channels, which can explain previous phenomenon for loperamide-induced prostatic relaxation (6). Therefore, the obtained results provide novel insights into the action mechanisms of loperamide particularly in the understanding of prostatic relaxation.

In conclusion, we suggest that activation of opioid $\mu-2$ receptors to open $\mathrm{K}_{\mathrm{ATP}}$ channels is responsible for loperamideinduced prostatic relaxation. Therefore, activation of peripheral opioid $\mu-2$ receptors may be a new target in the development of agents for the management of benign prostatic hyperplasia.

\section{Acknowledgements}

We thank Mr. K.F. Liu for the technical assistance. The present study was supported in part by a grant from Chi-Mei Medical Center (CLFHR9829).

\section{References}

1. Tiwari A, Krishna NS, Nanda K and Chugh A: Benign prostatic hyperplasia: an insight into current investigational medical therapies. Expert Opin Investig Drugs 14: 1359-1372, 2005.

2. Hellstrom WJ and Sikka SC: Effects of acute treatment with tamsulosin versus alfuzosin on ejaculatory function in normal volunteers. J Urol 176: 1529-1533, 2006.

3. Roehrborn CG, Marks LS, Fenter T, et al: Efficacy and safety of dutasteride in the four-year treatment of men with benign prostatic hyperplasia. Urology 63: 709-715, 2004.

4. Hanauer SB: The role of loperamide in gastrointestinal disorders. Rev Gastroenterol Disord 8: 15-20, 2008.

5. Corazziari E: Role of opioid ligands in the irritable bowel syndrome. Can J Gastroenterol 13: 71A-75A, 1999.

6. Cheng JT and Tong YC: Loperamide induced rat prostate relaxation through activation of peripheral opioid $\mu$-receptors. Neurourol Urodyn (In press).

7. Baker DE: Loperamide: a pharmacological review. Rev Gastroenterol Disord 7: S11-S18, 2007.

8. Nozaki-Taguchi $\mathrm{N}$ and Yaksh TL: Characterization of the antihyperalgesic action of a novel peripheral mu-opioid receptor agonist-loperamide. Anesthesiology 90: 225-234, 1999.

9. Tagaya E, Tamaoki J, Chiyotani A and Konno K: Stimulation of opioid mu-receptors potentiates beta adrenoceptor-mediated relaxation of canine airway smooth muscle. J Pharmacol Exp Ther 275: 1288-1292, 1995.

10. Ozdem SS, Batu O, Tayfun F, Yalcin O, Meiselman HJ and Baskurt OK: The effect of morphine in rat small mesenteric arteries. Vascul Pharmacol 43: 56-61, 2005.

11. Raimundo JM, Sudo RT, Pontes LB, Antunes F, Trachez MM and Zapata-Sudo G: In vitro and in vivo vasodilator activity of racemic tramadol and its enantiomers in Wistar rats. Eur J Pharmacol 530: 117-123, 2006.

12. Stefano GB: Endogenous morphine: a role in wellness medicine. Med Sci Monit 10: ED5, 2004.

13. Liu IM, Liou SS, Chen WC, Chen PF and Cheng JT: Signals in the activation of opioid mu-receptors by loperamide to enhance glucose uptake into cultured C2C12 cells. Horm Metab Res 36: 210-214, 2004.

14. Bova S, Trevisi L, Cima L, Luciani S, Golovina V and Cargnelli G: Signaling mechanisms for the selective vasoconstrictor effect of norbormide on the rat small arteries. J Pharmacol Exp Ther 296: 458-463, 2001. 
15. Cheng TC, Lu CC, Chung HH, et al: Activation of muscarinic M-1 cholinoceptors by curcumin to increase contractility in urinary bladder isolated from Wistar rats. Neurosci Lett 473 : $107-109,2010$

16. Teramoto N, Yunoki T, Ikawa S, et al: The involvement of L-type $\mathrm{Ca}(2+)$ channels in the relaxant effects of the ATP-sensitive $\mathrm{K}(+)$ channel opener ZD6169 on pig urethral smooth muscle. Br J Pharmacol 134: 1505-1515, 2001.

17. Mishra SK and Aaronson PI: A role for a glibenclamide-sensitive, relatively ATP-insensitive $\mathrm{K}^{+}$current in regulating membrane potential and current in rat aorta. Cardiovasc Res 44: 429-435, 1999.

18. Quayle JM and Standen NB: $\mathrm{K}_{\mathrm{ATP}}$ channels in vascular smooth muscle. Cardiovasc Res 28: 797-804, 1994.

19. Teramoto N: [Molecular and electrophysiological investigation of ATP-sensitive $\mathrm{K}^{+}$channels in lower urinary tract function: the aims for clinical treatment of unstable detrusor]. Nippon Yakurigaku Zasshi 121: 317-324, 2003.

20. Yang PS, Lee JJ, Tsao CW, Wu HT and Cheng JT: Stimulatory effect of stevioside on peripheral mu opioid receptors in animals Neurosci Lett 454: 72-75, 2009.

21. Zhang L, Bonev AD, Mawe GM and Nelson MT: Protein kinase A mediates activation of ATP-sensitive $\mathrm{K}^{+}$currents by CGRP in gallbladder smooth muscle. Am J Physiol 267: G494-G499, 1994

22. Uder M, Heinrich M, Jansen A, et al: cAMP and cGMP do not mediate the vasorelaxation induced by iodinated radiographic contrast media in isolated swine renal arteries. Acta Radiol 43: 104-110, 2002.

23. Wellman GC, Quayle JM and Standen NB: ATP-sensitive K+ channel activation by calcitonin gene-related peptide and protein kinase A in pig coronary arterial smooth muscle. J Physiol 507: 117-129, 1998 .

24. Liu IM, Chi TC, Chen YC, Lu FH and Cheng JT: Activation of opioid mu-receptor by loperamide to lower plasma glucose in streptozotocin-induced diabetic rats. Neurosci Lett 265: 183-186, 1999.

25. Chen JC, Smith ER, Cahill M, Cohen R and Fishman JB: The opioid receptor binding of dezocine, morphine, fentanyl, butorphanol and nalbuphine. Life Sci 52: 389-396, 1993.

26. Kristensen K, Christensen CB and Christrup LL: The mu1, mu2, delta, kappa opioid receptor binding profiles of methadone stereoisomers and morphine. Life Sci 56: PL45-PL50, 1995.
27. Cadet P: $\mathrm{Mu}$ opiate receptor subtypes. Med Sci Monit 10: MS28-MS32, 2004.

28. Mizoguchi H, Watanabe H, Hayashi T, et al: Possible involvement of dynorphin A-(1-17) release via mu1-opioid receptors in spinal antinociception by endomorphin-2. J Pharmacol Exp Ther 317: 362-368, 2006.

29. Sakurada S, Sawai T, Mizoguchi H, et al: Possible involvement of dynorphin A release via mul-opioid receptor on supraspinal antinociception of endomorphin-2. Peptides 29: 1554-1560, 2008.

30. Gintzler AR and Pasternak GW: Multiple mu receptors: evidence for mu2 sites in the guinea pig ileum. Neurosci Lett 39: 51-56, 1983.

31. Matsumoto K, Hatori Y, Murayama T, et al: Involvement of mu-opioid receptors in antinociception and inhibition of gastrointestinal transit induced by 7-hydroxymitragynine, isolated from Thai herbal medicine Mitragyna speciosa. Eur J Pharmacol 549: 63-70, 2006

32. Stefano GB, Hartman A, Bilfinger TV, et al: Presence of the mu3 opiate receptor in endothelial cells. Coupling to nitric oxide production and vasodilation. J Biol Chem 270: 30290-30293, 1995.

33. Oh SJ, Kim KM, Chung YS, Hong EK, Shin SY and Kim SJ: Ion-channel currents of smooth muscle cells isolated from the prostate of guinea-pig. BJU Int 92: 1022-1030, 2003.

34. Abdul M and Hoosein N: Reduced Kv1.3 potassium channel expression in human prostate cancer. J Membr Biol 214: 99-102, 2006.

35. Mannhold R: KATP channel openers: structure-activity relationships and therapeutic potential. Med Res Rev 24: 213-266, 2004.

36. Tsai CC, Lai TY, Huang WC, Liu IM and Cheng JT: Inhibitory effects of potassium channel blockers on tetramethylpyrazineinduced relaxation of rat aortic strip in vitro. Life Sci 71: 1321-1330, 2002.

37. Wong KL, Chan P, Yang HY, et al: Isosteviol acts on potassium channels to relax isolated aortic strips of Wistar rat. Life Sci 74: 2379-2387, 2004 